\title{
The effects of a specifically designed pre-school inclusion course on the attitudes of early childhood personnel
}

Kellie J. Morgan

West Virginia University

Follow this and additional works at: https://researchrepository.wvu.edu/etd

\section{Recommended Citation}

Morgan, Kellie J., "The effects of a specifically designed pre-school inclusion course on the attitudes of early childhood personnel" (2006). Graduate Theses, Dissertations, and Problem Reports. 4250.

https://researchrepository.wvu.edu/etd/4250

This Thesis is protected by copyright and/or related rights. It has been brought to you by the The Research Repository @ WVU with permission from the rights-holder(s). You are free to use this Thesis in any way that is permitted by the copyright and related rights legislation that applies to your use. For other uses you must obtain permission from the rights-holder(s) directly, unless additional rights are indicated by a Creative Commons license in the record and/ or on the work itself. This Thesis has been accepted for inclusion in WVU Graduate Theses, Dissertations, and Problem Reports collection by an authorized administrator of The Research Repository @ WVU. For more information, please contact researchrepository@mail.wvu.edu. 


\title{
THE EFFECTS OF A SPECIFICALLY DESIGNED PRE-SCHOOL INCLUSION COURSE ON THE ATTITUDES OF EARLY CHILDHOOD PERSONNEL
}

\author{
Kellie J. Morgan
}

Thesis submitted to the

Davis College of Agriculture, Forestry, Consumer Sciences

at West Virginia University

in partial fulfillment of the requirements for the degree of

\author{
Master of Science \\ In Family and Consumer Sciences \\ With an emphasis in \\ Child Development and Family Studies
}

Barbara G. Warash, Ed. D., Chair

Carol A. Markstrom, Ph. D.

Dottie D. Rauch M.Ed

Division of Family and Consumer Sciences

Morgantown, West Virginia

2006

Keywords: Preschool, Inclusion, Teachers Attitudes

Copyright 2006 Kellie J. Morgan 


\title{
THE EFFECTS OF A SPECIFICALLY DESIGNED PRE-SCHOOL INCLUSION COURSE ON THE ATTITUDES OF EARLY CHILDHOOD PERSONNEL
}

\author{
Kellie Morgan
}

The intent of this study was to examine the attitudes of early childhood personnel on preschool inclusion before and after participating in a preschool inclusion class that was specifically designed for preschool teachers. The attitudes of teachers were measured using a 7 point Likert type pre and post-assessment scale. The items on the scale dealt with the inclusion of children with disabilities in a typically developing classroom. The participants in the study included 96 early childhood personnel working in West Virginia. In this pre-experimental design, the total scores of each item for the pre-test were compared to total scores on each item for the post-test. In addition a paired $t$ test with Bonferroni correction for multiple comparisons was calculated for each of the seven items, which indicated that all pre-test versus post-test differences were significant along with the total scores at the $p<.01$ level. 


\section{Acknowledgments}

I would like to acknowledge my appreciation to the many people who contributed to this project. First, to Dr. Barbara G. Warash, my director, and chair person, who provided much appreciated guidance and support throughout this entire project even when my procrastination was unbearable. Also, many thanks to Dr. Carol Markstrom and Mrs. Dottie Rauch for contributing valuable comments, concerns and suggestions during this entire project. Much appreciation is extended to Dr. Reagan Curtis for his statistical assistance for the data analysis. His knowledge and patience made the statistics understandable, and almost simple.

I would also like to extend a special thank you to Melissa Pelliccioni and Diana Kingsbury for their constant support, encouragement, and patience. They both have the wonderful ability to make me laugh when tears are on the horizon.

A large thank goes you to my family and friends for the constant encouragement and support during the entire length of my college career.

Finally, to Bobbie Warash for giving me the opportunity to teach, learn, and experience WVU Lab Nursery School. 
Table of Contents

Page

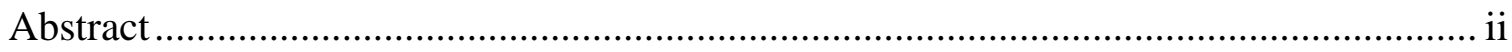

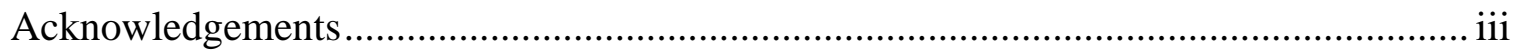

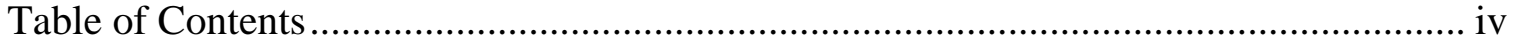

Chapter I

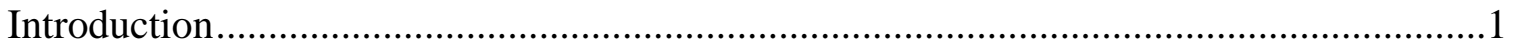

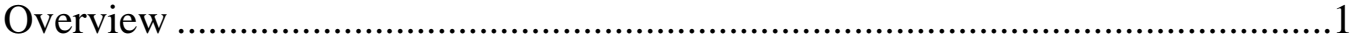

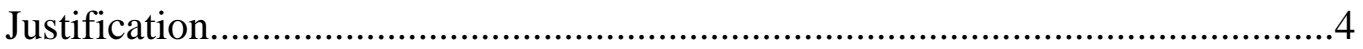

Statement of Problem ...................................................................................

Chapter II

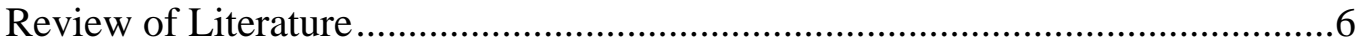

History of Inclusion.............................................................................6

Instructional Practices .......................................................................

Current Attitudes .................................................................................... 10

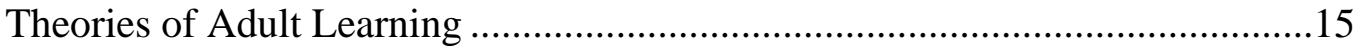

The Role of Adult Facilitators ...................................................................17

Chapter III

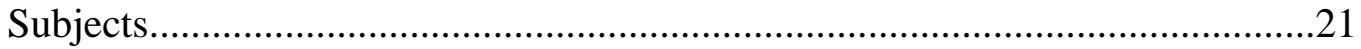

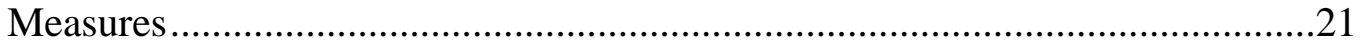

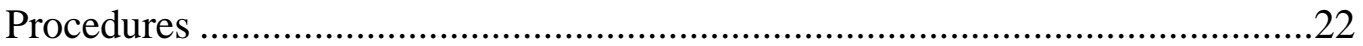

Chapter IV

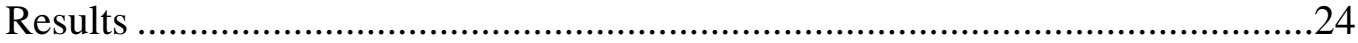

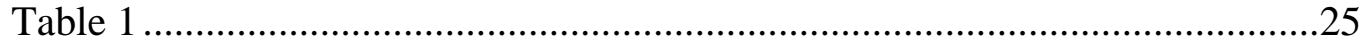

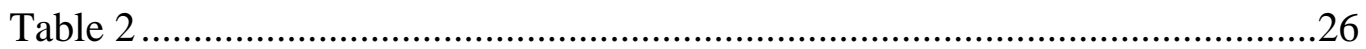

Chapter V

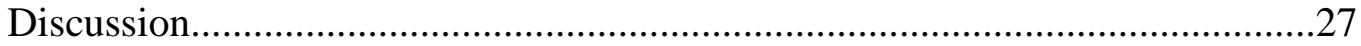

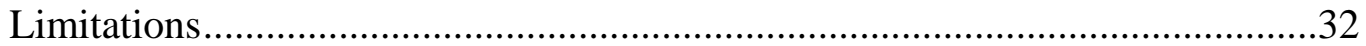

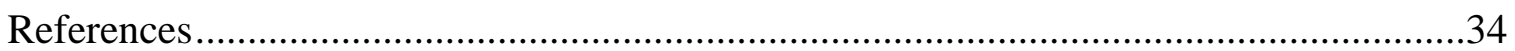

Appendices

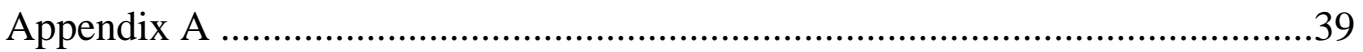

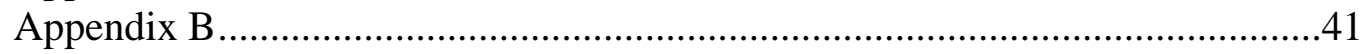


Chapter 1

Introduction

\section{Overview}

The value of including children with disabilities in programs with typically developing peers is beneficial to all children because preschool age children with and without disabilities are at a formative period for socialization (Circle of Inclusion, 2002). The concept behind inclusion is that children are their own best teachers and learn best from one another (Nagurski, 1998). Young children are not acquainted with the artificial boundaries of differences of children with special needs. Because of major mandates in public educational policy such as the Education for All Handicapped Children Act (PL 94-142) of 1975, teachers have more student diversity in the classroom. Public Law 94142 introduced the concept of the least restrictive environment and was reiterated in later amendments to include preschool aged children. Subsequent re-authorization became known as the Individuals with Disabilities Education Act (IDEA) (Osborne \& Dimattia, 1994). The hope is that when children with disabilities are educated alongside their peers, they might learn to imitate typical behaviors, mannerisms, and work habits (Nagurski). Although the federal and state legislative action related to IDEA such as requiring children with special needs be in the least restrictive environment as mandated by the law, legislators can not change the philosophical views of teachers. The treatment of children with special needs has a non-inclusive past. Prior to the middle of the twentieth century, society denied the existence of people with disabilities. Children with disabilities were kept out of sight and parents were encouraged to institutionalize the 
children. When special education became part of public schools curriculum, the program was considered custodial. Segregating children with special needs was the method of instruction until the 1990's and the passage of the American with Disabilities Act (Allen \& Cowdery, 2005). Educational practices have been embedded with a history of isolating the classroom and the instruction of children with disabilities.

Since segregation has been the norm for so long, some individuals are resistant to the change. Volk and Long (2005) refer to a term "deficit perspective” as the attitudes of educators who devalue and discount many children and families. Instead of focusing on the positive aspects of children with special needs, these educators center on labeling the children as deficient in language, culture or the ability to learn. This narrowed vision is perpetuated when educators label children as disadvantaged and at-risk. Even though Volk and Long have primarily used the term deficit perspective in relation to children and families from other cultures, the term also describes the negative attitudes of educators who work with young children with disabilities in a typical developing classroom.

A deficit perspective attributes failure to the children because the children are perceived as not equal. In contrast, a transformational perspective identifies values of the diverse community and builds on rich cultural practices to enhance teaching and learning. The transformation perspective needs to be used by early childhood educators in classrooms with children with disabilities.

While a conversion of attitudes is essential, there are trends that will facilitate this necessary transformation. According to Bradley and Kibera (2006) there are critical trends that are important in the preparation of early childhood professionals. These trends take into consideration the demographic changes of the family, the movement toward 
inclusion, and the increasing number of emotional and behavioral problems in preschool classrooms. Teachers are at a time when they must challenge or reinvent their thinking. The time for preschool inclusion has arrived, not only because it is the law but because it is the right thing to do. Professional educators must help early childhood personnel accept and absorb the benefits of inclusion for all young children.

In order for children to reap the benefits, preschool teachers need to rethink their methods of teaching and develop positive attitudes about inclusion in the classroom. West Virginia is striving to help teachers become ambassadors for preschool inclusion through the preschool inclusion classes that the West Virginia State Department of Education has implemented throughout the state. These classes are designed to use approaches that facilitate teachers to internalize the benefits of inclusion in the preschool classroom. We typically approach the teaching of children and adults differently recognizing that children and adults think and learn differently. However, in the present study the researchers incorporated approaches used in adult education, as well as approaches used in early childhood education.

Children’s approaches to learning represent observable patterns of behavior that are displayed while engaged in educational tasks (McDermott, Leigh, \& Perry, 2002). In contrast, adult learning styles are voluntary, collaborative, applicable, reflective and selfdirected (Brookfield, 1988).

The present study examined changes in attitudes of early childhood teachers as the result of a hands-on approach to learning. This approach is viewed as one that is more typically in the early childhood classroom. More specifically, the study examined the attitudes of early childhood personnel toward preschool inclusion to see if they could be 
altered as a result of a hands-on training approach. Many using Kolb’s (1984) theory of learning styles and the eight principles of adult learning identified by Moore (1988) and explained by Wolfe (1993). Kolb believed that learning styles could be seen on a continuum ranging from concrete experiences, to reflective observation, to abstract conceptualization, and to active experimentation (Litizinger \& Osif, 1992). Facilitators need to view learning styles on a continuum and understand that people move through this continuum over time but in the end prefer one style of learning over another.

\section{Justification for the Study}

Every individual whether it is a child or an adult has the right to an education. Therefore, children with disabilities have the right to an equal education. As a result of federal laws such as the Individuals with Disabilities Education Act (IDEA) which states that federal financial assistance must be provided to state and local agencies to guarantee special education and related services to children with disabilities (Henderson, 2001) and the West Virginia Board of Education Policy 2525, preschool teachers must realign their classrooms. It is justified that inclusive education is beneficial for children with disabilities and for typically developing children (Leiber et al., 1998). For non-disabled children, inclusion is an opportunity to experience diverse abilities and model their competencies in linguistics and social skills to the children with disabilities (Leiber et al.). With the demand that all children regardless of their disability or diversity in the same classroom, educators need to expand and adapt their knowledge of educational practices to include information about adapting the learning environment to fit the needs of a diverse student population (Deiner, 2005). In order for educators to expand their comprehension of inclusion, there must be proper training, which is the justification for 
the classes taught at West Virginia University, Concord College, Shepherd University, and Marshall University.

Statement of the Problem

In the state of West Virginia it is required that all children receive the same equal treatment and education in the classroom. According to the West Virginia Department of Education (2005), West Virginia is one of the first states to receive authorization for its plan to reach the goals proposed by the No Child Left Behind Act. It is mandatory that all preschool classrooms be inclusive by 2012 (West Virginia Department of Education, 2005).

The intent of this study is to compare preschool personnel's attitudes on preschool inclusion before and after a week long preschool inclusion course by examining the pre and post-assessment scales. The instruction was conducted on the campuses of West Virginia University, Shepherd University, Concord College and Marshall University during the summer of 2004. 


\section{Chapter Two}

Review of Literature

The review of literature is divided into four areas: (a) the history of inclusion, (b) the instructional practices, (c) the current attitudes of preschool personnel towards inclusion, (d) the theories of adult learning, (e) and finally adult facilitation.

\section{History of Inclusion}

The terms inclusive schools and inclusion are defined as follows. According to Stainback, and Stainback (1991), as found in Bauer, and Shea (1999) inclusive school is: A school in which all students are included in classes and are provided with 1) appropriate education experiences that are challenging yet are geared to students' capabilities and needs and 2) any support or assistance that they or their teachers require (p. 52).

Inclusion is defined by Sebba and Ainscow (1996) in Feiler and Gibson (1999):

Inclusion describes the process by which a school attempts to respond to all pupils as individuals by reconsidering its curricular organization and provision. Through this process, the school builds its capacity to accept all pupils from the local community who wish to attend and, in doing so, reduces the need to exclude pupils (p. 148).

Inclusion has traveled a long distance since the first investigation in 1817 when William Gallaudet created the first formal special education program in the United States 
(Minnesota’s Governor’s Council, 2004). During the middle to late 1800’s children with disabilities were provided with residential institutions in order to remove them from the public eye. By the year 1918 all states mandated state financed education for all individuals which created a nationwide public school system that guaranteed a free education for all (Minnesota’s Governor's Council). Unfortunately, children with disabilities were often excluded from these programs; however, when more students began attending, teachers soon realized that many of the children were learning at a slower pace. Teachers began demanding special services and training for these children.

In 1896 Rhode Island opened the first public special education class, and by the year 1923 around 34,000 children were enrolled in special education classes (Minnesota's Governor’s Council, 2004). In 1954, a landmark case was decided -Brown vs. The Board of Education. As the result of this victory, the United States Supreme Court decided that schools can not discriminate on the basis of race, in turn establishing that a separate education is not an equal education (Minnesota's Governor's Council). During the next twenty years, parents worked to improve the conditions of the state institutions, create community support, and initiate legislation but most importantly fought to erase the concept that children with special needs can not be helped (Minnesota's Governor’s Council). The Rehabilitation Act of 1973 and the Amendments of 1986 and 1992 guaranteed the rights of individuals with disabilities in the employment world and educational institutions that received funding from the federal government (Minnesota's Governor’s Council).

A major catalyst to the special education movement was the Individuals with Disabilities Education Act. As an amendment to the 1975 Education for all Handicapped 
Children Act the name was changed to The Individuals with Disabilities Education Act (IDEA) (Circle of Inclusion, 2002). IDEA guarantees that children with disabilities are educated with children who are not disabled. IDEA also promises that segregation of children with disabilities, separate schooling, and special services only occur when the severity of the disability is such that education in a general education classroom is not beneficial for the child.

An additional amendment under IDEA, is one adopted from previous legislation was the concept of least restrictive environment (LRE). The LRE guarantees that all children be educated in a setting that provides vast exposure to interactions with typically developing children and persons without disabilities (Minnesota’s Governor's Council, 2004), therefore, children with disabilities are given the most appropriate education. The years between 1975 and 1997 were long for parents and teachers who fought hard to ensure each child reached full potential in learning. IDEA was reauthorized 1997 and again in 2004, which required that an outline be supplied of the benefits and services obtainable by children with disabilities enrolled in private schools by their parents when Free Appropriate Public Education (FAPE) is not a concern (U.S. Department of Education, 2005). The law now makes certain that children with disabilities have the right to quality education and quality outcomes (Minnesota’s Governor's Council). Also included in the amendments of 1997 were definitions of aids and services, which included transportation and services to help a child with disabilities benefit from special education (Circle of Inclusion, 2002). This amendment also required that classroom teachers be included in the development of the IEP (Individualized Education Program), 
which is a guide for the child's education and enables the child to progress with regular curriculum (Circle of Inclusion).

\section{Instructional Practices}

Throughout history there have been a variety of teaching practices used in the classroom. One major practice is the idea of direct instruction, which is a model for teaching that emphasizes well developed and carefully planned lesson. These lessons are carefully planned around small learning increments and specifically agreed upon teaching tasks (National Institute for Direct Instruction, n.d.). The primary goal of direct instruction is to eliminate misinterpretations in order to accelerate learning.

Although direct instruction is valued in some classrooms, it has been the primary teaching strategy for children with disabilities. Preschool inclusive classrooms need to use direct instruction in conjunction with developmentally appropriate practice. According to Sandall, McLean, and Smith (2000) (as cited in Delaney), inclusion demands that early childhood educators have an extensive gamut of instructional teaching styles such as, peer mediated strategies, prompting procedures, behavioral correspondence, and language interventions. There are specific strategies involved in teaching children with special needs, these strategies or best practices should apply equally to all early childcare programs. These practices include strategies that are research based family centered, multicultural, cross cultural, normalized and developmentally appropriate (Allen, \& Cowdery, 2005). Normalized refers to providing opportunities for individuals with disabilities to attend school and actively participate in educational experiences just as typically developing children do. Developmentally 
appropriate practices, according to the Circle of Inclusion website (2002), are ways of providing an environment and offering content, activities, materials, and methodologies that are harmonized on a child's level of development. In all instances, according to Bredekamp and Copple (1997) (as cited in Delaney) the material should be taught in a developmentally appropriate manner, with an assessment of the overall program needs, and the level of development of the children being served.

Fortunately, early childhood educators have adopted the idea of developmentally appropriate methods such as learning through play and a more hands-on approach. One key factor in developmentally appropriate practices is age and individual appropriateness. Activities in the classroom need to be realistic to the attention span and capabilities of the child. One prime example of using developmentally appropriate practice with typically and non-typically developing children is Toni Linder's concept of Read, Play, and Learn, which capitalizes on children's natural preferred activity - play. According to Linder, play can be used to promote and augment the acquisition of pre-literacy skills. All children are united by play. There are two natural interests of children according to Toni Linder in Read, Play, and Learn (2000); the first instinct of children is to learn about their environment and communicate learned knowledge to others, while the second is to increase the number of ways that knowledge can be acquired and shared. Allowing children to explore and acquire knowledge through learning and making choices, then being able to reiterate this information to others is justification that the material is learned. Basically, the main objective is to put the acquired knowledge to work in the environment.

\section{Current Attitudes}


In order to implement developmentally appropriate practices in the inclusive classroom teachers must possess a positive attitude towards inclusion. Attitude, as described by the Merriam Webster Online dictionary (2005-2006), is a person's mental position or emotion toward a truth or state. The attitudes of preschool teachers vary according to the training received. Since inclusion is mandatory, many teachers are searching for adequate training for setting up an inclusive classroom. A preschool teacher's job is to teach academics but more importantly their job is to encourage and extend the children's navigation into the world (Hess, 2003). With this task in mind teachers are concerned with the lack of knowledge they have about children with disabilities, how to incorporate these children into their classroom, (Odom, 2000) and using effective teaching methods. There has been a history of using direct instruction and applied behavior analysis (Tucci \& Hursh, 1991) with children of special needs. In contrast early childhood teachers are constantly searching for effective methods to teach in the classroom but most are not knowledgeable on ABA. Preschool teachers are expected to be accepting, enthusiastic imaginative, positive, and flexible decision makers who honestly believe that all children are more similar than different and can all learn in the same environment with modifications (Deiner, 2005). These are high standards for teachers who feel incapable of providing a quality education to children with and without disabilities.

In December of 1999, The Teacher Training Agency recognized the need for more specific training for teachers in order for them to meet the needs of the children with more complex needs and to support other teachers working in the mainstream classroom (Sadler, 2005). In a questionnaire survey by Marshall, Ralph, and Palmer 
(2002) of 200 post-graduate student teachers, the number one obstacle of inclusion is the lack of training especially in language and speech, along with the complaint of a need for resources.

Also, in a study conducted by Seery, Johnson, \& Lawrence (2000), fifty-two early childhood professionals and parents were surveyed, interviewed, observed, and evaluated. The total sample for the study consisted of 52 adults, 22 of whom were teaching professionals and support staff. The remaining 30 were composed of parents of typically developing children and children with disabilities, all enrolled in the preschool program. Some of the issues that comprised this study included the comfort and discomfort levels of teachers concerns with inclusion and the teachers and parents perceptions about the benefits and methods of inclusion. Also included in the study were the concerns about the needs for specific training for inclusion and how to access appropriate services for children. The goal was to uncover differences between two groups of stakeholders, teaching professionals/school support staff as one group and parents as the other group. The researchers investigated the perceptions of the two groups regarding the benefits and concerns about inclusion as their preschool undertook a new phase of inclusion of children with disabilities. The results from the two phases of interviews were compared in order to describe changes in perception over the course of the academic year. It was clear, by the end of the study, that both parents and staff strongly supported the notion that inclusion programming was good for children and should continue. Since inclusion has been deemed successful with the right strategies, teachers must practice different teaching methods, such as individualized lessons. 
As a result of individualized lessons, children's experiences in the same classroom are different because the setting is individually appropriate for the child (Odom, 2000). The quality of these individualized settings is a reflection of the child's engagement in the classroom routines, the program characteristics, and the quality of the program including staff training (Odom).

The main intent of learning, according to Ferguson, Meyer, Jeanchild, Juniper, \& Zinger (as cited in Bauer \& Shea, 1999) in inclusive settings is to enable all students to participate actively in their community so that others care enough about the individual and look for ways to include them in those communities. The success of the classroom is dependent on the teacher's knowledge. However, the teachers knowledge is greatly influenced by the attitudes and beliefs held by the teacher. A study presented by Lieber, et al. (1998), investigated the beliefs and benefits of inclusion by interviewing 23 preschool teachers. This study was part of a multi-site ecological investigation of inclusion in early childhood environments conducted by the Early Childhood Institute on Inclusion (ECRII). For the purpose of this study, researchers utilized qualitative and quantitative procedures to look at four different programs that involve young children with and without disabilities. The study involved 16 programs but only 14 subsets were employed for this particular paper. From those 14 programs, 23 classrooms and 29 teachers were observed. The results of the study indicated that children with disabilities were considered a part of the classroom, were given supports in order to participate in classroom activities, and instructions were modified if necessary to support children with disabilities. Although, all teachers believed that all children were members of the classroom, there were varying degrees to which teachers allowed and respected 
individual choices. The beliefs seemed to differ in how the classroom was viewed: as group of many individuals or a group norm that needs to be followed. According to the teachers who believed that the classroom was a group of individuals, there was a wider range of freedom to be an individual, while those with the view of a group norm, the level of acceptance in the group was limited. In the end, the overall consensus was that inclusion was beneficial to all students and it provided a learning opportunity for all involved. The teachers also agreed that inclusion promoted an awareness and recognition of diversity. The diversity allowed for the nurturance of typically developing children in the areas of empathy, tolerance, and compassion. Finally, it was concluded that children with disabilities should be members of the group and will learn though the peer modeling of typically developing children.

In the same respect, understanding the views of the parents is just as important as understanding the beliefs of the teachers. In a study by Stoiber, Gettinger, and Goetz, (1998), the realization of the need to understand parents and early child hood educator's beliefs about inclusion in the early childhood classroom. For the study a total of 415 parents and 128 early childhood practitioners were involved and drafted from 10 early childhood inclusion programs in Wisconsin. The parents and educators involved in the study were asked to complete a survey (My Thinking about Inclusion) about their current beliefs on inclusion. Two versions of the survey were provided, one 12 item scale used for the parents and one 28 item comprehensive scale used for practitioners. Both scales included a demographics section and beliefs about inclusion section. The reliability analysis of the scale resulted in the following alphas- Core Perspective, Expected Outcomes, Classroom Practices, and Total Scores. 
The results of the study concluded that parents with children who had disabilities scored the survey more positively than those parents whose children were typically developing. The results also showed significant associations between socio- economic status (SES) and positive views of inclusion. Those who were in the high to middle SES scored more positive than those with low SES. For the practitioners, there was an association made between regular and special education teachers scoring more positively than the paraprofessionals, and on the classroom practices subscale. Also, special educators were more positive than paraprofessionals on the Core Perspective and Total scale. In the analysis it was concluded that education and experience shape the views of inclusion, therefore, educators with training in special education and regular education shared a more positive outlook on inclusion than did paraprofessionals. In the same respect, early childhood practitioners with only a high school degree had a less positive view about implementing inclusion than those practitioners with extensive training. Theories of Adult Learning

Time must be spent on how to successfully and appropriately re-teach educators on how to conduct in an inclusive classroom. For the past five years researchers with Early Childhood Research Institute on Inclusion (ECRII) (Leiber et al., 1998) have focused on children with special needs in early childhood settings. The goal of ECRII is to identify facilitators and barriers to inclusion in the classroom (Odom et al., 1996) so teachers can create a thriving learning atmosphere.

In order for adult education classes to succeed the facilitators must understand how adults learn and acquire knowledge. Research and theories on adult learning provide valuable information on how to effectively engage an interdisciplinary audience (Catlett 
\& Winton, 1999). There must be a direct correlation between the activity and the practice context (Moore, 1988) and the activities should be responsive to a variety of learning styles (Wolfe, 1993).

Researchers such as Litzinger and Osif (1993) also understand the importance of differing learning styles. They understand that children and adults develop a preferred learning style and a consistent behavior to learning. Litzinger and Osif break the learning process into three processes- cognition, conceptualization, and affective learning. Cognition deals with how one acquires knowledge while conceptualization is how one processes the information and takes into consideration that people often look for connections to unrelated events, or that each event prompts a multitude of new schemes (Litizinger \& Osif ). Finally, the affective domain is defined as peoples’ motivation, decision making styles, and emotional and value preferences which help to define their learning styles.

In the same respect, Kolb (1984) devised his Theory of Learning Styles on a continuum made up of four parts starting with concrete experiences. The concrete experiences are those experiences which are new to the individual. Second, reflective observation involves watching others or expanding on one's own experiences. Third, is abstract conceptualization or the generating of new presumptions to explain observations. Last on the continuum is active experimentation, which involves the use of theories to explain a problem or make independent decisions (Kolb, 1984).

Hartman (1995) explained the application of Kolb’s theory of learning. For example, the concrete learner would benefit from field work or laboratories, while the abstract conceptualizer might profit from lectures and handouts. The active experimenter 
benefits from simulations and homework, while the reflective observer uses journals, and brainstorming to acquire knowledge.

Although adults learn in different styles than children, we can adapt theories of children’s learning to adult learning, such as the zone of proximal development theorized by Vygotsky (1978) (as cited in Kalmar, 2005). The zone of proximal development is a component of Vygotsky's social learning theory. Although it was originally applied to children, it can also be applied to fit adult learning. According to Vygotsky (as cited in Kalmar), the zone of proximal development is the distance between the actual developmental level, as determined by independent problem solving, and the level of potential development as determined through problem solving under adult guidance or in collaboration with more capable peers. Adults can learn in their zone of proximal development with the right guidance and the collaboration of other peers who are on the same level or above or below that level. Adults must be willing to think on another level to acquire new knowledge. Therefore, an individual will learn continuously or move to the next level of thinking if the material is expounded.

\section{The Role of Adult Facilitators}

Teachers directly teach and fine tune the skills to help students succeed in the outside world (Hess, 2003). Once these life skills have been mastered, the child puts them to use in the larger school community and, as a result, students are one step closer to independence (Hess). Unfortunately, there is no way to predict the results of these children as adults but the more we practice life skills in schools the better the chance of success in the real world (Hess). 
Obviously teachers are capable of teaching simple life skills; however the challenge is that teachers have not always been prepared in their training for the responsibilities that accompany inclusive learning. Pre-service teachers face incredible challenges; often these challenges are faced alone. As a result, nearly half of all newly hired teachers leave the teaching profession within the first five years (DarlingHammond, 1997). Teacher educators need to recognize that one of the main components in teacher education is self-study of one's own teaching practices with support from peers (Kosnik, Beck, Freese, \& Samaras, 2005). Self-study is a professional tool that educators can utilize for learning and modifying their approaches to teaching; it can also be used as a way for overwhelmed beginning teachers to focus on one or two areas to improve upon in their own classroom, rather than focusing on the larger picture of the educational world (Kosnik et al., 2005). The goal for most modern professional development efforts is to improve performance by the organization, staff, and eventually the student (Sparks, 1994). Adult learning can be more productive if the educator understands the basic guidelines to teaching adults.

According to Moore’s (1988) Guidelines for Adult Learning and Wolfe’s (1993) Research on What Works, there are eight principles of learning for adults. The first principle of adult learning is that learning is enhanced when it can be immediately applied to real life situations (Moore; Wolfe). According to this principle Moore and Wolfe encourage educators to allow the students to put the new skill to use through activities, collaboration, problem solving skills and assessments. The second principle involves the aspect of control: If the adult has control or influence over the educational experience, then learning is enhanced (Moore; Wolfe). This involves choices-partner 
selection for group work, allowing participants to set time schedule (breaks), the group sets the ground rules, and offer opportunities for participants to test out of assessments (Moore; Wolfe). The third principle incorporates the past and current experiences that shape learning, such as encouraging evolution through timelines, reports in attitude changes, and role playing. The fourth principle encourages the adult to take an active role in the experience in order for learning to be enhanced (Moore; Wolfe). The fifth principle is based on comfort and respect, for example, offer refreshments, create an inviting room setting, pay attention to room temperature, and provide comfortable tables and chairs (Moore; Wolfe). The next rule of adult learning is self-direction of the participant, which encourages the facilitator to offer self appraisals, establish on-going connection, and create support networks among the participants. The seventh principle can be incorporated into the sixth one, which involves creating connections or team training, small groups, and co-presenting. Finally, the educator should take into consideration the different learning styles, and the individual differences of the learner.

An adult's willingness to learn, acquire new skills, and participate in classroom activities broadens what a facilitator can do in adult classroom. Brookfield (1988) identified six principles of effective practice in facilitating learning for adults. Brookfield recommends that facilitators should allow for voluntarily participation, collaboration, and continual learning practices. In order to encourage learning, facilitators also need to allocate time for critical reflection and nurture self-directed learning. Finally, Brookfield believes that respect among the learners is critical to a successful classroom.

Fortunately, the learning principles of adults are observable in a variety of settings such as training, continuing education classes, self-directed learning, community action, 
and networks (Brookfield, 1988). Some of the major tasks involved in teaching adults are presenting the learners with alternate ways of thinking, behaving, living, teaching, and setting a climate for learning in which individuals feel free to challenge each other and are comfortable being challenged (Brookfield). These challenges from within the group should lead to very important self reflections and critical thinking in the classroom. This reflection is encouraged through continuous learning, investigation, and exploration and continues through a constant cycle (Brookfield). The exploration of new ideas is set within the context of the learners, past, present and future experiences (Brookfield). According to Brookfield, education must be separated from training. Training is the assimilation of new skills, while education is examining the assumptions underlying the skills and being able to apply them to a broader context.

In summary, training needs to be done to help early childhood personnel learn to accept the process of inclusion. How this training is implemented varies, but should incorporate adult education models (Kolb, 1984; Moore, 1988; Wolfe, 1993) as well as methods of engaging the early childhood teacher (Vygotsky, 1978).

The history of special education and early childhood inclusion has not surged together. With the demand to make fully inclusive environments by 2012 in West Virginia, a hands-on class was developed to prepare early childhood personnel. This study investigated the changes of attitudes as a result of a summer institute in preschool inclusion. Therefore, the hypothesis is that the attitudes of early childhood personnel will change as a result of a specifically designed preschool inclusion class as reflected on a seven point Likert-type assessment scale. 


\section{Chapter 3}

\section{Methods}

\section{Subjects}

The participants for this study consisted of 96 teachers and personnel working with young children in the State of West Virginia. The participants consisted of early childhood teachers, special education teachers and other early childhood workers. The participants were enrolled in one of the preschool inclusion classes taught at four institutions of Higher Education in West Virginia. The class size was limited to 25-30 participants in each of the four locations. There were 27 participants enrolled at West Virginia University, 28 teachers enrolled at Concord State College, 33 teachers enrolled at Marshall University and 28 teachers at Shepherd College. Thirty Seven participants were taking the course for undergraduate credit and 59 were taking it for graduate credit.

\section{Measures}

The participants were given a pre-assessment scale on the first morning of class to evaluate their attitude towards preschool inclusion. The assessment scale (appendix A) had the participants rate a statement on including children with disabilities on a 7- point Likert type scale of various descriptors such as; easy to hard, and include all to include none. The same assessment was given on the last day of class. The pre-and post assessment scale was developed by a special needs educator contracted through the West Virginia Department of Education. The assessment was based on the scale developed by 
Dr. David Puzzuoli (1993) for the Eisenhower Program of the Ohio Board of Regents to examine changes in teacher attitudes.

\section{Procedures}

Professors from four West Virginia Higher Education Institutions were contracted through a West Virgina Department of Education grant to develop the preschool inclusion class. The instructors met three times prior to the classes in order to discuss the content and methods of teaching. The West Virginia Department of Education required that the classes cover the same objectives and involve a parent of a child with a disability in the teaching and development of the class. Involving a parent was a unique strategy to help participants understand a child's disability through the parent's perspective. Required content for the class included: (a) collaboration with specialists (b) laws regarding special education, (c) parent involvement, (d) individual education plans, (e) adaptive activities within a play environment, (f) specific disabilities, and (g) resources. The overall intent of the class was to build a positive image of preschool inclusion, help teachers be more comfortable with children who have disabilities, and to help early childhood personnel to understand that a disability is to be accepted and not fixed. The teaching strategies were more of an unorthodox teaching approach such as, using a hands-on approach, guest speakers, role playing and collaboration with peers that would engage the adult learners. In each class small groups were formed to provide opportunities for interactions with each other. For example, at West Virginia University, the class was divided into base groups consisting of four or five of the participants. The groups consisted of teachers who normally do not work together in order to facilitate 
additional learning opportunities with peers. Instead of tests, there were projects where participants worked in their base groups. The parameters around the projects were given but there was a degree of freedom for the participants to expand in various directions as long as the requirements were met. The class at WVU met at the University Nursery School, while the other classes used campus classrooms. There were refreshments available and funds to provide supportive resources for the participants to use in their projects. The classes were held as a one-week institute during the summer in order that practicing teachers could attend. All participants received college credit and the course was free.

All procedures and instruments received WVU Institutional Review Board approval before the study was implemented (see Appendix B). 


\section{Chapter 4}

\section{Results}

This was a pre-experimental design study comparing the total scores of each item for the pre-test to the total scores on each item for the post- test. The study was based on seven statements regarding the inclusion of children with disabilities into regular preschool classrooms that were measured on a 7 point scale with 1 being the highest score and 7 being the lowest. The scores were expected to decrease from the pre-test to the post -test.

Total scores for each item were calculated across participants. The mean of the pre-test scores ranged from 1.83 on item 5 to 4.45 on item 3 , while the mean of post-test scores ranged from 1.18 on item 5 to 3.24 on item 3 (See Table 1). The standard deviations of the pre-test scores ranged from 1.06 on item 2 to 1.20 on item 7 , while the standard deviations of the post-test scores ranged from 0.44 on item 5 to 1.23 on item 2 . An examination of Table 1 reveals that the mean pre-test scores were consistently higher than the mean post-test scores.

The mean difference between the pre and post- test scores on each item was calculated and these differences ranged from .60 for item 4 to 1.21 for item 3 (See Table 2). A paired $t$ test with Bonferroni correction for multiple comparisons was calculated for each of the seven items, which indicated that all pre-test versus post-test differences were significant along with the total scores at the $p<.01$ level. Specific t-values and degrees of freedom for each test are provided in Table 2. 
Table 1

Means (Standard Deviations) of Each Item at Pre-test and Post-test

\begin{tabular}{lll}
\hline Item & Pretest & Posttest \\
\hline Include All to Include None & $2.69(1.16)$ & $1.87(.85)$ \\
Easy to Hard & $4.37(1.06)$ & $3.19(1.22)$. \\
Simple to Complicated & $4.45(1.07)$ & $3.23(1.07)$ \\
Worthwhile to Wasteful & $1.85(1.12)$ & $1.25(.49)$ \\
Beneficial to Harmful & $1.83(1.08)$ & $1.19(.44)$ \\
Learn through Play to Learn through Direct Instruction & $2.37(1.15)$ & $1.45(.69)$ \\
I Feel Capable to I Don't Feel Capable & $3.16(1.20)$ & $2.10(.90)$ \\
Total Scores & $2.97(.67)$ & $2.05(.51)$ \\
\hline
\end{tabular}


Table 2

Mean Differences (Standard Deviations) from Pre-test to Post-test, Observed t-value and Degrees of Freedom for Each Item

\begin{tabular}{llcc}
\hline Item & Difference & t-value* & df \\
\hline Include All to Include None & $.81(1.20)$ & 6.21 & 82 \\
Easy to Hard & $1.18(1.53)$ & 7.06 & 83 \\
Simple to Complicated & $1.21(1.31)$ & 8.50 & 83 \\
Worthwhile to Wasteful & $.60(1.07)$ & 5.12 & 83 \\
Beneficial to Harmful & $.65(.98)$ & 6.15 & 83 \\
Learn through Play to Learn through Direct Instruction & $.91(1.20)$ & 6.85 & 81 \\
I Feel Capable to I Don’t Feel Capable & $1.06(1.18)$ & 8.17 & 82 \\
Total Scores & $.92(.72)$ & 11.79 & 83 \\
\hline
\end{tabular}

*Note: All differences significant at the $p<.01$ level with Bonferroni correction for multiple comparisons. 


\section{Chapter 5}

\section{Discussion}

As Bradley and Kibera (2006) suggested there are important issues in the preparation of early childhood professionals. The movement towards inclusion is one of those issues. It is important to understand the attitudes and beliefs of early childhood teachers because these attitudes influence the process of change, which in this case, is including children with disabilities in the preschool classroom.

The intent of this study was to determine the effects of a specially prepared course that utilized various methods of instruction and how that instruction changed the attitudes of early childhood personnel towards preschool inclusion. The results of the study supported the hypothesis: A preschool inclusion course for early childhood personnel that incorporated various teaching strategies positively affected the attitudes of preschool personnel towards inclusion. The overall statement on the 7 -point Likert type assessment scale distributed to the participants stated, "How do you currently feel or think about each of the statements regarding children with disabilities in the regular preschool classroom?” The statement referred to the following items: include all to including none, easy to hard, simple to complicated, worthwhile to wasteful, beneficial to harmful, learning through play to learning through direct instruction, and feeling capable to not feeling capable.

Of course, it was not expected that the ratings on the assessment scale would be rated at a one but rather there would be a change in the ratings from the pre-and post assessment scale. The significant changes of all the items could be attributed to several factors. All the instructors maintained a positive environment where participants could 
interact and collaborate with each other. All instructors of the preschool inclusion classes used similar materials and hands- on teaching strategies in the courses. Providing a nonthreatening environment is one of the principles that educators need to provide young children in the classroom. This same principle of an informal environment was effective in the adult preschool inclusion classroom. Vygotsky’s (1978) social learning theory reiterates that individuals need to collaborate with more capable peers. The courses provided opportunity for collaboration by doing group projects. Groups worked together to be creative and create support networks. These strategies were consistent with the adult education methods suggested by Moore (1988) and Wolfe (1993) where participants can set some ground rules and teach others. Because these courses were taught in a comfortable environment and geared towards the adult learning styles, the participants could have been more receptive of the information.

As stated earlier, the opportunity for collaboration as suggested by Moore (1988) and Wolfe (1993) was a predominant part of the courses. Stoiber, Gettinger and Goetz (1998) found that limited time and opportunities for collaboration were barriers to learning about inclusive environments. Practitioners need peer support and ongoing opportunities for professional development where they can learn from each other. In this study, participants were grouped with peers they did not know so they could interact with each other as they completed their group projects. This opportunity helped the participants to reflect and expand on their experiences which is beneficial to the learner as suggested by Brookfield (1988), who also suggests that self directed learning and a constant learning cycle is best for the adult learner. 
For the early childhood instructors of the courses, the pre-and post ratings on "play" was a victory for early childhood and proved to be one of the successes of the course. Recently, play has been down played by parents and some early childhood teachers because of the demand for academic success in preschool. Theorists and child development experts such as Vygotsky (1978) and Piaget (1970) recognize the importance of play and how it is a necessary entity in the child's development. The attitude toward learning through play became stronger after the class. This was especially rewarding for the instructors of the courses who concentrated on play as an opportunity for teaching appropriate skills. Using early intervention methods that "weave" intervention into the child's environment in a meaningful way is monumental. Direct instruction and applied behavior analysis (Tucci \& Hursh, 1991) has had a hold on special education teaching strategies for years. The classes had many special education teachers as well as early childhood teachers. Special education participants have a background in direct instruction which is diverse from early childhood participants, who are trained in developmentally appropriate practice. Early childhood teachers do not generally use direct instruction in their classrooms as it is not recommended by such organizations as the National Association for the Education of Young children (NAEYC) (Bredekamp \& Copple, 1997). Early childhood teachers, prior to the class may have felt threatened by thinking direct instruction was going to be the only route they would have to take in teaching young children with disabilities while developmentally appropriate practice would occur with typically developing children. The special education teachers, prior to the class may have also felt threatened by their limited amount of expertise in developmentally appropriate practice. This type of confusion could have caused some 
negativity on the pretest but at the end of the course, teaching methods were made clearer. The instructors of the course emphasized play and how to modify "direct instruction" with children of disabilities into the setting without interrupting the child's natural desire to play. This model of professional development helped teachers come to an understanding that this is not an either or issue, but rather a convergence of teaching methods. This study is consistent with Stoiber, Gettinger and Goetz (1998) who found that direct hands-on experiences was the most preferred method for improving inclusion practices. Direct instruction does not meet the practical needs of early childhood teachers. Bernheimer and Koegh (1995) described a model called "weaving interventions into the fabric of everyday life” (p. 42). This is similar to the philosophy of Toni Linder who developed the Read, Play and Learn series for inclusive environments. Dr. Linder, in Read, Play, and Learn (2002), had a theoretical shift from a drill and skill model for children with disabilities to one that is play based. She advocates that children should learn by exploring their world and interacting with peers through the use of dramatic play, sensory motor activities, science experiments and outdoor games. These activities encourage children to express themselves freely, learn though play, and share their knowledge with peers.

In addition to modifying and explaining appropriate teaching strategies that may have helped to alleviate fears of preschool teachers, the involvement of a parent of a child with a disability in all the courses gave first hand information to the class participants. The parent involvement could help to explain the change of the items on the assessment scale dealing with the continuum of being "easy" to "hard", "beneficial" to "harmful", "simple" to "complicated" and "whether children with disabilities should be included or 
not included in regular preschool classrooms”. Having a parent to help with the class could have brought a certain level of comfort to the participants. Instruction from a parent with a child with disabilities may have helped participants to accept the differences between children with and without disabilities. The parents involved in teaching were perhaps able to communicate that all children in inclusive environments gain knowledge about disabilities and become more accepting of children with disabilities. The parent helped with the development of positive attitudes toward children with disabilities and the development for strategies of interacting and working with children with disabilities. The parent reiterated that children with disabilities do have social skill deficits but the involvement of their children in the community and the establishment of friendships is vital. Parents of children with disabilities might agree academics are important but inclusion is only an initial step, social participation is a need that must be met as it is life skill. Building social networks for the child with a disability is the most important action. All children need a sense of connection with others. There needs to be a deliberate strategy to involve their children with peers. These types of thoughts from a parent brought a new level of understanding from the parent's point of view.

Dr. Barbara G. Warash (personal communication, March 01, 2006), it was revealed that the concern of many of the participants was how to successfully incorporate the typically developing children with the children who have disabilities. By the institute's use of hands-on activities, the preschool participants were able to see how a child with a disability fits into an inclusive classroom. The participants of the class were challenged to be "disabled” in a classroom and think as a child, which provided them with a more realistic view of how a child with disabilities fits into a classroom. The 
concerns of the teachers were softened as a result of the inclusion classes as revealed in the results of this study.

Several themes emerged as a result of this research. First, a non-threatening adult classroom using various methods of adult education can be beneficial for early childhood educators. It can alleviate some fears which may help to change negative attitudes. Second, there needs to be a greater philosophical congruence between the fields of early childhood education and early childhood special education because these teachers who were once teaching in their own domains are now teaching in inclusive classrooms. Katie Berry, a graduate of special education and coordinator of a local Starting Points early childhood program, states that because she was trained in special education but works in an early childhood program that must be developmentally appropriate, she understands the confusion educators are experiencing (personal communication, April 6, 2006). Educators from these diverse fields need training on methods of implementing a combination of teaching strategies. The benefits of supporting an inclusive environment will be reflected once educators come to an agreement on the debate surrounding inclusion. At this point, it will infiltrate to the public and community. Third, involving a parent of a child with a disability was a novel way of helping the participants to understand the needs of their children from the parent's perspective.

\section{Limitations}

There are several limitations in this study. The first limitation is the assessment scale that was used. A scale with various individual statements measuring more precise beliefs would have revealed more information. A scale that measured the teacher's beliefs on outcomes for an inclusive classroom and classroom practices would have also 
strengthened the study. A second limitation was the limited demographic information available on the participants. More information would have been useful in delineating the educational level of the participants. For example, in the research by Stoiber, Gettinger, and Goetz (1998), teachers with master’s degrees had a more positive attitude. It is unknown if this would have been a finding in this study had more information been collected on the assessment scale? Follow-up interviews would have also given the researcher more information about the retention of changes in attitudes.

In conclusion, inclusive early childhood programs have potential benefits for communities as well as to the children participating on the classroom. Giangreco (1996) said that by including all children with disabilities in preschool, we are developing a new generation that experiences the diversity presented by the disability as a routine part of everyday life (p. 207). The important part is that this concept needs to be well planned and accepted or it can have negative effects on children with and without disabilities. 


\section{References}

Allen, K.E., \& Cowdery, G. E. (2005). The exceptional child: Inclusion in early childhood education (5th ed.).Clifton Park, NY: Thomson Delmar Learning.

Bauer, A.M., \& Shea, T.M. (1999). Inclusion 101: How to teach all learners. Baltimore, MD: Brookes Publishing Co.

Bernheimer, L. P., \& Koegh, B.K. (1995). Weaving interventions into the fabric of everyday life: An approach to family assessment. Topic in Early Childhood Special Education, 15, 415-433.

Bradley, J., \& Kibera, P. (2006). Closing the gap: Culture and the promotion of inclusion in child care. Young Children, 61, 34-40.

Bredekamp, S., \& Copple, C. (Eds.). (1997). Developmentally appropriate practice in early childhood programs ( Rev. ed.). Washington, DC: NAEYC

Brookfield, S. (1988). Understanding and facilitating adult learning. School Media Quarterly, 16, 99-105.

Catlett, C., \& Winton, P. (1999). Resources within reason: Materials that support teams in providing effective services. Young Exceptional Children, 2, 27.

Darling-Hammond, L. (1997). The right to learn: A blueprint for creating schools that work. San Francisco: Caddo Gap Press.

Deiner, P. (2005). Resources for educating children with diverse abilities; Birth through eight ( 4th ed). Clifton Park NY: Thomson Delmar.

Delaney, E. M. (2001). The administrator's role in making inclusion work. Journal of the National Association for the Education of Young Children, 56, 66-70.

Feiler, A., \& Gibson, H. (1999). Threats to the inclusive movement. British Journal of 
Special Education, 26, 147-151.

Ferguson, D.L., Meyer, G., Jeanchild, L., \& Zingo, J. (1992). Figuring out what to do with the grownups: How teachers make inclusion "work" for students with disabilities. Journal of the Association for Persons with Severe Handicaps, 17, 218-226.

Giangreco, M. F. (1996). Extending the "Comfort Zone” to include every child. Journal of Early Intervention, 20, 206- 208.

Hartman, V. F. (1995). Teaching and learning style preferences: Transitions through technology. VCCA, 9, 18-20.

Henderson, K. (2001). An overview of ADA, IDEA, and Section 504: Update 2001. The Eric Clearing House on disabilities and gifted education. Retrieved June 6, 2004, from http://ericec.org.

Hess, K. (2003). Keep the change: A hard earned success. Journal of the National Association for the Education of Young Children, 58, 30-32.

Kalmar, K. (2005). Preservice teachers’ co-constructed alternative to shhh! Association for Childhood Education International, 6,1-3.

Kansas Inservice Training System (KITS). (2002). Circle of inclusion. Retrieved March 9, 2006, from University of Kansas, Circle of Inclusion Project Web site: http://circleofinlcusion.org

Kolb, D. A. (1984). Experiential Learning: Experience as the source of learning and development. New Jersey: Prentice Hall.

Kolbs, D. A. (1985) Learning styles- self inventory: Self scoring inventory and interpretation booklet. Boston: McBer Company. 
Kosnik, C., Beck, C., Fresse, A. R., \& Samaras, A. P. (2005). Making a difference in teacher education through self-study: Studies of personal, professional, program renewal. The Netherlands: Springer Publishers.

Lieber, J., Capell, K., Wolfberg, S. P., Horn, E., \& Beckman, P. (1998). Inclusive preschool programs: Teachers' beliefs and practices. Early Childhood Research Quarterly, 13, 87-105.

Litzinger, M, and Osif, B. (1993). Accommodating diverse learning styles: Designing instruction for electronic information sources. ed. Shirato, L., What is Good Instruction Now? Library Instruction for the 90s. Ann Arbor, MI: Pierian Press.

Marshall, J., Ralph, S. and Palmer, S. (2002). I wasn't trained to work with them: Mainstream teachers 'attitudes to children with speech and language difficulties. Journal of Inclusive Education, 6, 199-215.

McDermott, P. A., Leigh, N. M., \& Perry, M. A., (2002). Development and validation for the preschool learning behaviors scale. Psychology in the Schools, 39, 353-365.

Merriam-Webster Online Dictionary. (n.d.). Retrieved March 9, 2006, from http://www.m-w.com/dictionary/attitude

Minnesota’s Governor's Council on Developmental Disabilities. (2004). Partners in Education: History of education. Retrieved February 12, 2006, from http://www.partnersinpolicymaking.com/education/history_overview_sb.html

Moore, J.R. (1988). Guidelines concerning adult learning. Journal of Staff Development, 9, 1-5.

National Institute for Direct Instruction. (n.d.). Retrieved March 1, 2006, from http://www.nifdi.org 
Odom, S. (2000). Preschool inclusion: What we know and where do we go from here. Topics in Early Childhood Special Education, 20, 20-28.

Odom, S., Peck, C., Hanson, M., Beckman, P., Kaiser, A., Lieber, J., Brown, W., Horn, E., Schwartz, I. (1996). Inclusion at the preschool level: An ecological systems analysis. SRCD Social Policy Report, 10, 18-30.

Osborne, A. G., \& DiMattia, P. (1994). The IDEA’s least restrictive environment: Legal implications. Exceptional Children, 61, 6- 14.

Piaget, J. (1970). Piaget's theory. In P.H. Mussen (Ed.), Handbook of child psychology ( $4^{\text {th }}$ ed.) (Vol.1,W.Kessen, Ed.). New York: John Wiley, 1983

Read Play \& Learn. (2002). Play and literacy. Retrieved March 9, 2006, from http://www.readplaylearn.com/philosophy/playandliteracy.htm

Sadler, J. (2005). Knowledge, attitudes, and beliefs of the mainstream teachers of children with a pre-school diagnosis of speech/language impairment. Child Language Teaching \& Therapy, 21, 147-163.

Sandall, S., McLean, M.E., \& Smith, B.J. (2000). DEC-recommended practices in early intervention learly childhood special education. Longmont, CO: Sopris West.

Sebba, J., \& Ainscow, M. (1996). International developments in inclusive schooling: Mapping the issues. Cambridge Journal of Education, 26, 5-17.

Seery, M. A., Johnson, P.M., \& Lawrence, J. (2000). Seeing eye -to- eye. Remedial \& Special Education, 21,268

Soriano-Nagurski, L. (1998). And the walls came tumbling down: Including children who are differently abled in typical early childhood educational settings. Journal for the Association for the Education of Young Children, 53, 40-41. 
Sparks, D. (1994). A paradigm shift in staff development. Journal of Staff Development, 15, 26-29.

Stainback, S., \& Stainback, W. (1991). Schools as inclusive communities. In W. Stainback \& S. Stainback (Eds.), Controversial issues confronting special education: Divergent perspectives (pp. 29-43). Needham Heights, MA: Allyn \& Bacon.

Stoiber, K. C., Gettinger, M., \& Goetz, D. (1998). Exploring factors influencing parents’ and early childhood practioners' beliefs about inclusion. Early Childhood Research Quarterly, 13, 107-124.

Tucci, V., \& Hursh, D. (1991). Competent Learner Model: instructional programming for teachers and learners. Education and Treatment of Children, 14, 349-361.

U.S. Department of Education. (2005, November). Today's focus IDEA amendments of 2004. Retrieved April 6, 2006, from U.S. Department of Education Web site: http://www.ed.gov/parents/needs/special/onpe/idea04/edlite-slide003.html

Volk, D., \& Long, S. (2005). Challenging myths of the deficit perspective: Honoring children's literacy resources. Journal for the Association for the Education of Young Children, 60, 12-19.

Vygotsky, L. (1978). Mind and society: The development of higher psychological processes. Cambridge, MA: Harvard University Press.

West Virginia Department of Education. (2005). A Message from the Superintendent. Retrieved October 12, 2005, from http://wvachieves.k12.wv.us/

Wolfe, B. (1993). In service best practices: research on what works and what does not. Eau Claire, Wisconsin: author. 
Appendix A

Preschool Inclusion Summer Institute Pre/Post Test Evaluation 


\section{PRESCHOOL INCLUSION SUMMER INSTITUTE PRE/POST TEST EVALUATION}

Date:

Location: West Virginia University

Name:

My skills and abilities in fully including young children with disabilities into regular preschool and other community settings were enhanced by additional preparation in : (check all that apply)

The benefits and challenges of inclusion.

The federal and state laws that govern inclusion, preschool special and regular education, Head Start, child care, etc.

The impact of inclusion on children with disabilities.

The impact of inclusion on children without disabilities.

Working collaboratively with families of children with disabilities.

Working collaboratively with other agencies.

Developmentally Appropriate Practices.

Quality early childhood programs

Setting up the inclusive preschool environment.

Activities and strategies to include children with disabilities in regular preschool classrooms.

Making adaptations to materials and the classroom environment.

Dealing with challenging child behaviors.

Helping children with disabilities and their families as they move from one program or

service to another.

Other (Please List)

Indicate with an " $\mathrm{x}$ " how you currently feel or think about each of the statements regarding including children with disabilities into regular preschool classrooms.

For example: easy _ _ _

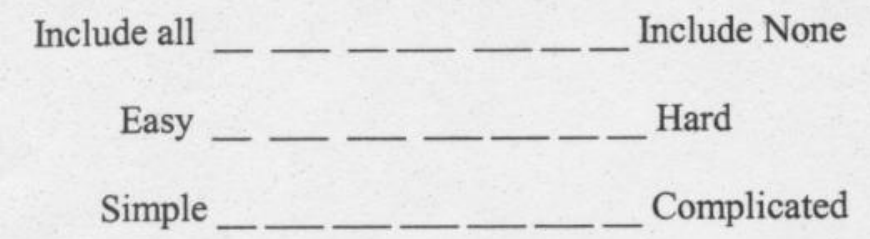

Worthwhile ___ _ _ _ _ _ Wasteful

Beneficial ___ _ _ _ _ _ _ Harmful

Learn through Play _____________ Learn through direct instruction

I feel capable ___ _ _ _ _ _ I don't feel capable 
Appendix B

International Review Board Approval 
Office of Research Compliance

Date: November 14, 2005

\section{MEMORANDUM}

To: Barbara Warash

DCAFCS/Family \& Consumer Science

From: Lilo Ast,

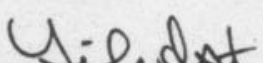

Senior Program Coordinator

Re: $\quad$ 16770-E; The Changes in Attitudes of Early Childhood Teachers as a Result of Training on Preschools Inclusion

The Institutional Review Board for the Protection of Human Research Subjects (IRB) finds the above names research project qualifies as an exemption.

This finding will remain in effect only on the condition that the research is carried out exactly as described in the Application. Please submit an amendment to the IRB office if you intend to modify or change your study in any way. Any amendment must be reviewed and acknowledged before initiating any changes or modifications

Best wishes for the success of your research.

$\mathrm{LAA} / \mathrm{clg}$ 